\title{
Radiofrequency Ablation for Atypical Cartilaginous Tumors is safe and effective: analysis of 189 consecutive cases
}

\author{
Nijland $\mathbf{H}^{1}$, Overbosch $\mathrm{J}^{2}$, Ploegmakers JJW ${ }^{1}$, Kwee $\mathrm{TC}^{\mathbf{2}}$ and Jutte PC ${ }^{\mathbf{1}}$ \\ ${ }^{1}$ Department of Orthopaedic Surgery, University Medical Center Groningen, The Netherlands \\ ${ }^{2}$ Department of Radiology, University Medical Center Groningen, The Netherlands
}

*Corresponding author: Nijland H, Department of Orthopaedic Surgery, University Medical Center Groningen, The Netherlands

\begin{abstract}
Objective: The purpose of this study was to investigate the efficacy and safety of radiofrequency ablation (RFA) as a less invasive treatment alternative for atypical cartilaginous tumors.

Materials and methods: Data of all consecutive RFA procedures for atypical cartilaginous tumors between 2007-2018 were analyzed, including temperature, amount of needle positions and ablation time per position. Tumor volume was measured on preoperative MRI and ablation zone was assessed on 3-month postprocedural MRI. RFA outcome parameters were ablation result (R0: complete with margin ( $\geq 2 \mathrm{~mm})$, R1: complete without margin $(<2 \mathrm{~mm})$ and R2: incomplete) and occurrence of complications.

Results: In $84.4 \%$ of cases complete ablation was achieved (66.7\% R0, 17.7\% R1). In 15.6\% of procedures ablation was incomplete (R2). No recurrences were seen after R0/1 ablations (with minimum two years follow-up). R0 was achieved significantly more frequent in smaller tumors $(\mathrm{p}=.027$, odds ratio $(\mathrm{OR})=1.04($ per $\mathrm{cm} 3)$ and with longer ablation time per needle $(\mathrm{p}=.048, \mathrm{OR}$ $=.894)$. Temperature $>80^{\circ} \mathrm{C}(\mathrm{p}=.026, \mathrm{OR}=7.57)$ resulted in more complete (R0 or R1) ablations without increasing complication rate $(\mathrm{p}=.579)$ compared to temperature of $71-80^{\circ} \mathrm{C}$. In 15 procedures $(7.9 \%)$ a complication occurred.

Conclusion: RFA provides promising results for treatment of atypical cartilaginous tumors with complete ablation (R0, R1) in $84.4 \%$ of procedures. Complication rates are comparable with open surgery and the amount of fractures is lower. These encouraging data support the potential of RFA to replace more invasive surgical approaches.
\end{abstract}

\section{Introduction}

Chondrosarcoma is the second most commonly diagnosed primary bone tumor in adults (after osteosarcoma), with a reported incidence of 8.78 per 1 million people [1-2]. They are often found coincidently by MR, X-ray or CT imaging for unrelated musculoskeletal symptoms [3]. Incidence increases proportionally with the amount of imaging that is performed in the population [4]. They can be divided into three grades based on histology combined with macroscopic imaging features. Grade- 1 central chondrosarcomas in long bone are called atypical cartilaginous tumors (ACTs) and are usually asymptomatic [3]. These tumors can show locally aggressive growth, but metastases are very uncommon. Prognosis of ACT is favorable, with 3-year overall survival of $96 \%$ and 5-year overall survival of 93\% [2].
Since ACTs are resistant to both radiotherapy and chemotherapy, the first choice of treatment for these tumors has been surgical, either by curettage or wide resection [5-6]. Recent literature showed wide resection to be necessary only for tumors with local aggressive growth [3]. A systematic review analyzing 214 curettage procedures for ACT reported a success rate (i.e. no recurrent or residual tumor) of $90.2 \%$, with a complication rate of $4.8 \%$ (6 out of 126, of which five fractures) [5]. For wide resection complications reportedly occurred in 24 out of 76 cases $(=31.6 \%)$ [5]. In a large Cochrane analysis, a success rate of $93.2 \%$ was found for curettage and $94.6 \%$ for wide resection [7]. In our center we found comparable results in 108 patients, as described by Dierselhuis et al. [3]. Recently, a wait- and see policy with radiological follow-up has also been advocated [8]. 
With less invasive treatment functional outcome is better, especially when limbs and joints can be preserved. Furthermore, overall patient satisfaction is better, complication risk lower, weight bearing is often not restricted, and hospitalization period is shorter for minimally invasive procedures [9-10].

Radiofrequency ablation (RFA) has already been used in soft tissue, primarily liver, for a long time. Application to bone tissue has so far mainly been in treatment of osteoid osteoma [11-14]. In RFA tumor tissue is destroyed by local application of electricity, causing motion, friction and heat and thereby causing coagulative necrosis. The principle is based on the fact that (irreversible) tissue damage starts at a temperature of $47^{\circ} \mathrm{C}$ and instantaneous protein denaturation starts at $60^{\circ} \mathrm{C}$ (Figure 1 ).
Literature on RFA for treatment of bone malignancies is limited and mainly focused on metastases [15-17]. Knowledge on safety and efficacy of RFA treatment for ACTs, especially for larger tumors, needs to be expounded. The aim of the current paper is to present the data that were acquired over the last 12 years in the treatment of ACT using RFA. Recommendations regarding safety and effectivity of RFA for ACTs are provided.

(Figure1): Tissue reaction to heat. [18-20] Ideal temperature for ablation is $60-95^{\circ} \mathrm{C}$ because instant cell death is the aim. Above $100^{\circ} \mathrm{C}$ charring occurs, limiting conduction of heath and thereby limiting the slow cooking effect of slow heat flow into the surrounding [21].

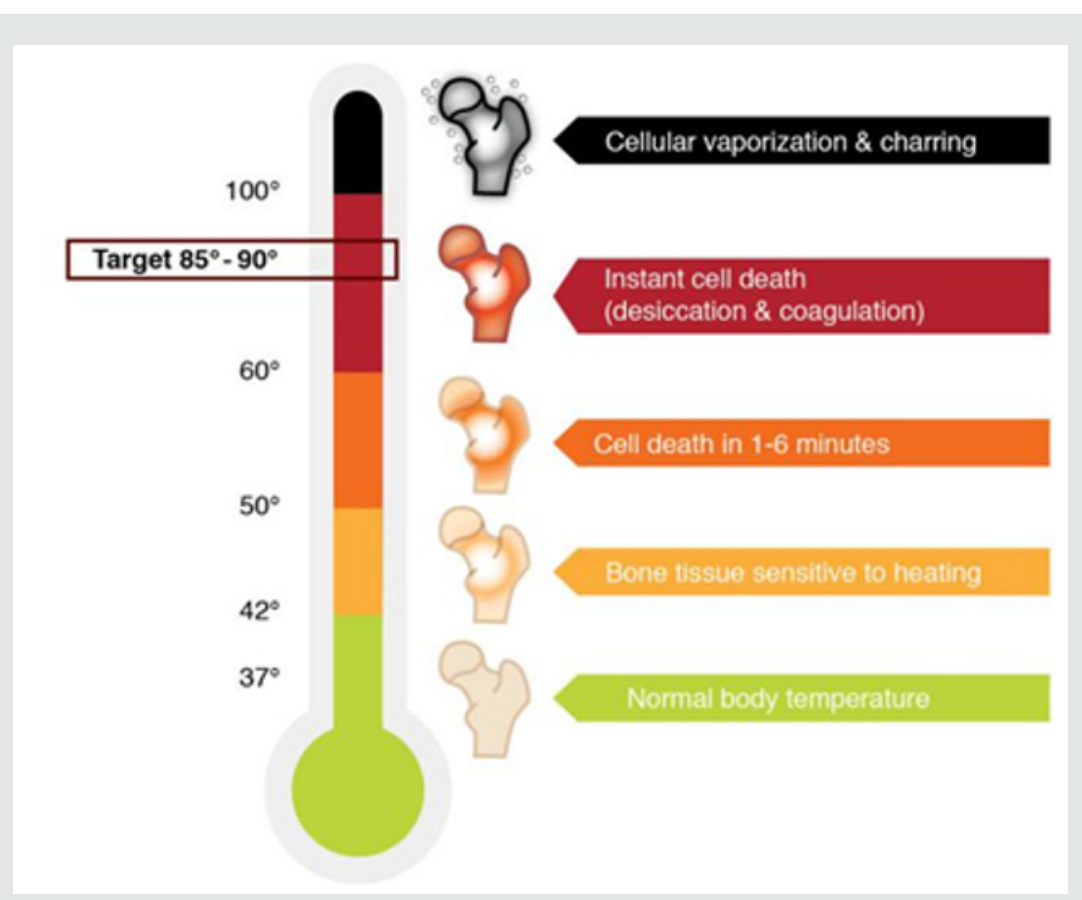

Figure 1: Tissue reaction to heat [18-20] Ideal temperature for ablation is $60-95^{\circ} \mathrm{C}$ because instant cell death is the aim. Above $100{ }^{\circ} \mathrm{C}$ charring occurs, limiting conduction of heath and thereby limiting the slow cooking effect of slow heat flow into the surrounding [21].

\section{Method}

\section{Procedure}

Pre-RFA diagnosis of ACT was made based on imaging. On MR images they typically appear as a completely intramedullary located, popcorn-like lesion, with septonodular and peripheral enhancement after gadolinium-based contrast agent administration and limited scalloping. On T2-weighted imaging the chondroid components of an ACT appear as areas of high signal intensity. Perilesional edema and cortical breakthrough are signs of higher grade [22]. RFA was carried out in the department of radiology using CT guidance or in the operation room (OR) using fluoroscopy guidance or computer assisted surgery (CAS). This decision was dependent on tumor localization, size and comorbidities. Tumors with diameter over $6 \mathrm{~cm}$ were generally treated in the OR because of the possibility to place a prophylactic osteosynthesis to prevent fracture. Procedures were carried out under anesthesia. First a tract was drilled towards the tumor and a histological biopsy was performed to confirm the radiological diagnosis. Then an RFA needle was brought up towards the tumor and ablation was carried out. For the ablations from 2007-2014 a Boston Scientific RF3000 needle was used, from 2015-2019 a Cooltip needle (Medtronic). Parameters like ablation time per position and temperature were pre-operatively determined for every single procedure based on location in the bone, proximity to sensitive structures (cartilage, nerves, and vessels) and volume of the tumor. After the procedure these parameters were documented in the electronic patient file. Immobilization was only advised after procedures in the pelvic region. For all other procedures three months sports restriction (contact- and indoor sports) was advised. 
At three months, baseline MR (consisting of unenhanced T1weighted, fat-suppressed T2-weighted and gadolinium-enhanced sequences in two perpendicular planes with 4-mm slice thickness) was made to determine the exact ablation area. Subsequent followup MR scans were planned one, two, five and seven years after the procedure. For assessment of long-term effectivity only the data of the 85 patients with at 20 months follow-up was used.

\section{Data Collection}

Data, including histology results, from all consecutive RFA procedures carried out in our center in a 12-year period (20072018) were retrospectively collected from the prospectively kept local bone tumor database and the patient files. In accordance with regulations of the Medical Ethical Review Board of University Medical Center Groningen (UMCG), patients were informed by means of written information about the fact that anonymized data of the procedure could be used for scientific research in case they did not object. On pre-RFA MR images the tumor dimensions were measured on T1- and T2-weighted scans. The observer was blinded for final outcome during measurement. In three cases there was no pre-RFA MR. these cases were excluded from the tumor volume analysis. Treatment success (i.e. tumor completely within the RFA halo on all MR sequences and slices) was determined on MR images three months after RFA by a radiologist. Furthermore, the location in the bone (diaphysis, metaphysis, and epiphysis) and whether the tumor completely covered the distance between the medial and lateral cortices (i.e wall to wall) was determined. From the tumor dimensions the volume was calculated using the following formula:

$$
\begin{aligned}
& \mathrm{V}=(\mathrm{p} \cdot \mathrm{r} 2) \cdot \mathrm{H} \\
& \mathrm{V}=\text { volume } \\
& \mathrm{r}=\text { radius } \\
& \mathrm{h}=\text { height }
\end{aligned}
$$

Since most tumors were elliptical (see Figure 2) the formula was split up:

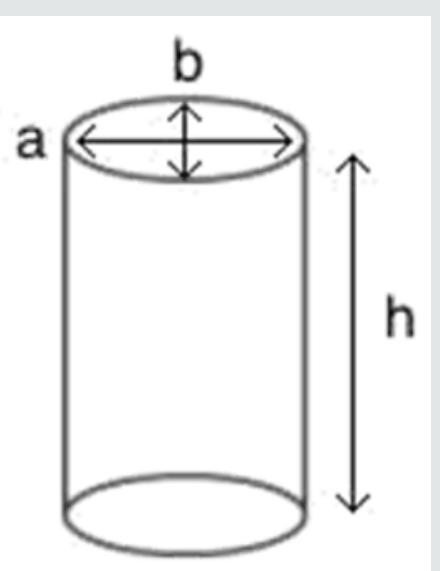

Figure 2: Animation of tumor dimensions for calculating volume.

$$
\begin{aligned}
& \mathrm{V}=(\mathrm{p} \cdot 1 / 2 \cdot \mathrm{a} \cdot 1 / 2 \cdot \mathrm{b}) \cdot \mathrm{h} \\
& \mathrm{a}=\text { width } \\
& \mathrm{b}=\text { depth }
\end{aligned}
$$

Which could be abbreviated to?

$V=1 / 4 \cdot p \cdot a \cdot b \cdot h$

This formula describes the volume of an elliptical cylinder in $\mathrm{mm} 3$; values were divided by $10^{\wedge} 3$ to be converted to $\mathrm{cm} 3$.

\section{Data Analysis}

Outcome parameters were technical success and complications. We divided the technical success into three groups, according to Dierselhuis et al. [23]. Group 1 comprised complete ablations with a margin $\geq 2 \mathrm{~mm}$ and was called R0, group 2 (R1) comprised complete ablations with a margin $<2 \mathrm{~mm}$, and group 3 (R2) comprised of incomplete ablations (tumor visible outside the ablation zone or halo) (Figure 3). In our analysis we looked at the influence of peri-procedural parameters, including tumor volume, age, ablation time per position, temperature, amount of needle positions, wall to wall filling (i.e. from cortex to cortex), type of bone and location within the bone. Evaluation of tumor volume was preferred over maximum diameter because we think volume provides a better approximation of actual tumor size when determining if a tumor is suitable for RFA treatment. Maximum diameter possibly underestimates tumor size, especially for round tumors. In case of an $\mathrm{R} 0$ result, the ablation was considered technically successful, in case of R2 unsuccessful. R1 can be considered successful as well in case there is no local recurrence within two years (research with prolonged follow-up is ongoing). However, treatment aim was initially set at R0. Therefore, analysis was done for both R0 vs R1/2 and R0/R1 vs R2. We also analyzed the association between the peri-procedural parameters and a complication in general to occur, as well as between these parameters and a fracture (which was the most frequent complication). Applied temperature was divided into three groups $\left(60-70,71-80,81-90^{\circ} \mathrm{C}\right)$.
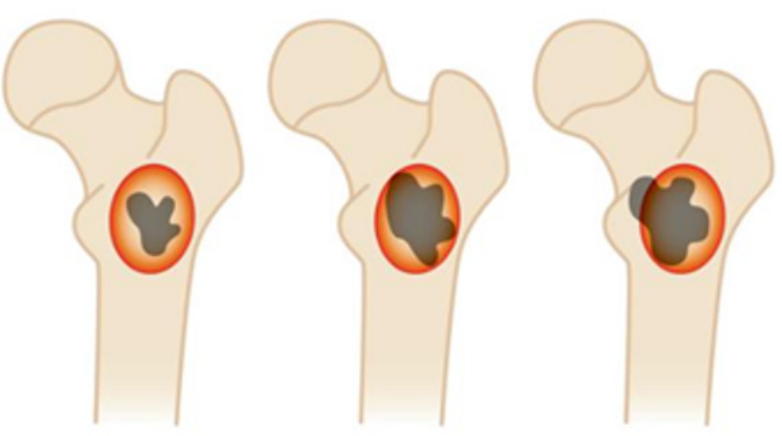

Figure 3: The 3 post-RFA result groups. R0 = complete ablation with $\geq 2 \mathrm{~mm}$ margin, R1 = complete ablation with $<2 \mathrm{~mm}$ margin, $\mathrm{R} 2=$ incomplete ablation . 


\section{Statistical Analysis}

Data were analyzed using SPSS Statistics v20 (IBM, Armonk, United States). Data were tested on normality of distribution and for correlation between variables. Analysis on the influence of periprocedural variables on result and complications was done using univariate logistic regression. Odds ratios, confidence intervals and p-values were reported. For temperature we compared the $81-90^{\circ} \mathrm{C}$ groups to the other two groups. Variables with p-value <.10 were included in a multivariate logistic regression. Furthermore, the odds ratios from logistic regression were used to look for a cut-off point for tumor volume (to determine if there is a maximum tumor volume from which the result is significantly worse). For all tests an alpha of .05 was chosen.

In figure 4 the RFA procedure is illustrated as well as images of an ACT with and without needles in situ and a 3-month post-RFA baseline T1-weighted MR.
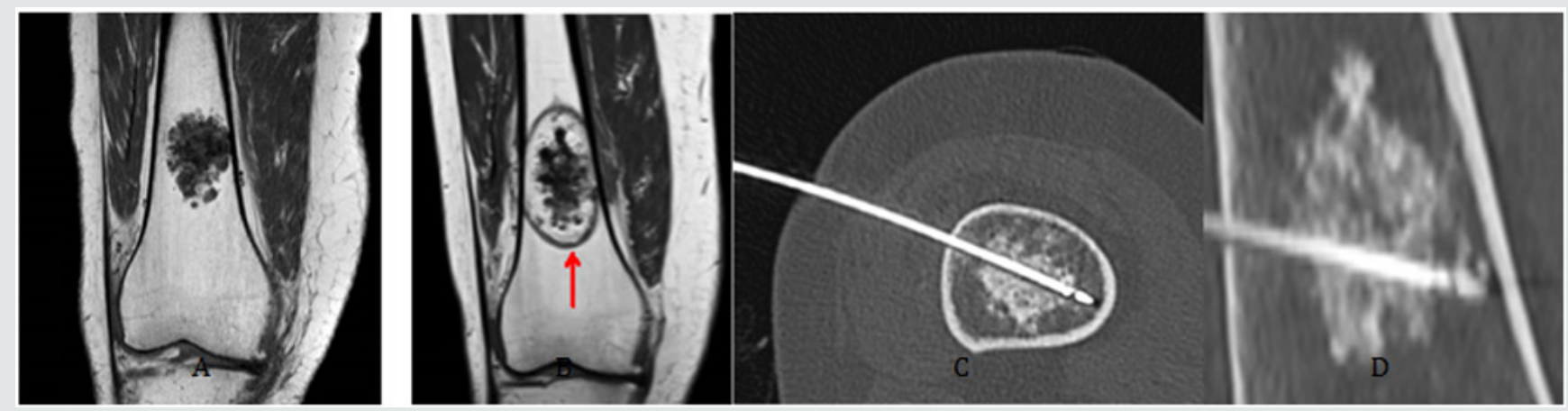

Figure 4: Radiofrequency ablation of an atypical cartilaginous tumor. A: MR image of an ACT in distal femur.B: MR baseline, 3 months after RFA procedure. The red arrow indicates the ablation halo. C: Transverse oblique CT image with RF needle in situ. D: Sagittal oblique CT image with RF needle in situ.

\section{Results}

Since 2007, 189 RFA procedures (in 187 patients) were carried out as treatment for ACT at the UMCG. Of these procedures 163 were performed percutaneously (using CT-guidance) and 26 open. For three procedures baseline MRI was lacking for various reasons (explained in more detail later). Between 2009 and 2014 a pilot

Table 1: Summary of most important peri-procedural parameters was carried out in which 44 patients received a combination of RFA treatment followed by MRI after three months and intralesional curettage two to six weeks later $[11,23]$. These patients are included in the current analysis as well. Of the 189 procedures, 129 were in the femur, 39 in the humerus, 19 in the tibia, one in the fibula and one in the acetabulum. (Table 1) gives a summary of the most important peri-procedural parameters.

\begin{tabular}{|c|c|}
\hline Variable & Value \\
\hline Procedures & 189 \\
\hline Male/Female & $58 / 131$ \\
\hline Follow-up time (months) & $17.1(3.88-32.6)$ \\
\hline Age (years)** & $53.3( \pm 12.3)$ \\
\hline Tumor volume (cm3)* & $8.69(4.51-16.4)$ \\
\hline Maximum diameter (mm)* & $29.0(23.0-40.5)$ \\
\hline Result (R0 / R1 / R2) & $124 / 33 / 29$ \\
\hline Complications & 15 \\
\hline Recurrences after R0 / R1 & 0 \\
\hline Needle positions* & $2.00(2.00-3.00)$ \\
\hline Temperature $\left({ }^{\circ}\right.$ C) & $83.3( \pm 9.13)$ \\
\hline Total ablation time (minutes)** & $20.0( \pm 15.0)$ \\
\hline Ablation time / position** & $9.10( \pm 3.05)$ \\
\hline CT / fluoroscopy / CAS*** & $163 / 18 / 8$ \\
\hline Location*** (D / DM / M / ME / E / DME) & $40 / 32 / 82 / 29 / 3 / 2$ \\
\hline Wall to wall (yes/no) & $70 / 118$ \\
\hline
\end{tabular}




\section{Treatment result}

In 124 procedures $(=66.7 \%) \mathrm{R} 0$ was achieved. In 33 procedures $(=17.7 \%)$ the result was $\mathrm{R} 1$ and 30 procedures $(15.6 \%)$ were $\mathrm{R} 2$. In six patients 3-month post-RFA baseline MR was not made due to debilitating amyotrophic lateral sclerosis $(n=1)$, death from another disease $(n=1)$, or complications $(n=4$ : one avascular necrosis $(A V N)$, two fractures (which necessitated surgical intervention with curettage and a plate) and one thermal skin injury (which necessitated surgical intervention)). The RFA result of these latter three cases was determined based on pathology at the time of surgical re-interventions. For the minimally invasive procedures 107 resulted in R0 (66.5\%), 29 in R1 (18.0\%) and 25 in R2 (15.5\%). In four of the patients with $\mathrm{R} 2$ result a re-ablation was carried out. In three cases this led to complete ablation (three times R0), one patient still had a small residue. Considering the size $(15 \times 10 \times 8 m m)$ of this residue a wait and see policy was chosen. Follow-up showed no progression at 5 years after the procedure. (Table 2) depicts the effects of peri-procedural parameters between the three different treatment outcomes (R0, R1, R2). No correlations of $>.50$ were found between any variables. Based on univariate logistic regression for $\mathrm{R} 0$ vs $\mathrm{R} 1 / 2$, tumor volume ( $\mathrm{p}=.033)$, time per position ( $\mathrm{p}=.048)$, location on the transition of diaphysis to metaphysis $(p=.036)$ and tumors reaching from wall to wall ( $p=.072)$ were included for multivariate analysis. In multivariate analysis only volume ( $p$ $=.0450$ and mean time per position $(\mathrm{p}=.013)$ had a significant effect. Larger tumor volume and shorter time per position lead to more incomplete (R1/2) ablations. The R2 of this multivariate model is .153 , indicating only $15.3 \%$ of variance in result R0 vs $\mathrm{R} 1 / 2$ is due to the variables in the model. From the ablations with temperature between $60-70^{\circ} \mathrm{C} 68.4 \%$ resulted in $\mathrm{R} 0$, for $71-80^{\circ} \mathrm{C}$ this was $70.0 \%$ and for $81-90^{\circ} \mathrm{C} 75.0 \%$. Only $5.4 \%$ of ablations over $80^{\circ} \mathrm{C}$ resulted in $\mathrm{R} 2$, compared to $17.2 \%$ for ablations up to $80^{\circ} \mathrm{C}$. Based on univariate analysis for R0/1 vs R2 a temperature of 71$80^{\circ} \mathrm{C}$ (compared to $\left.>80^{\circ} \mathrm{C}\right)(\mathrm{p}=.026)$ and mean time per position $(\mathrm{p}$ $=.063$ ) were included for multivariate analysis. No variables had a significant effect on R0/1 vs R2. The multivariate model had an R2 of .171. For the 85 procedures (R0 or R1) with minimum 20 months follow-up no signs of residual tumor or recurrence were seen on MRI (median: 32.5 months, range: 20.0-115.4 months).

Table 2: Effect of most important peri-procedural parameters on treatment result (R0 vs R1/2 \& R0/1 vsR2).

\begin{tabular}{|c|c|c|c|c|}
\hline Parameter & Univariate OR (95\% CI) & P-value & Multivariate OR (95\% CI) & P-value \\
\hline \multicolumn{5}{|l|}{ R0 vs R1/2 } \\
\hline Tumor volume ${ }^{E}$ & $1.03(1.00-1.07)$ & 0.033 & $1.04(1.00-1.09)$ & 0.05 \\
\hline Age ${ }^{Æ Æ}$ & $1.00(.977-1.03)$ & 0.9 & & \\
\hline 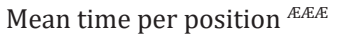 & $.894(.800-1.00)$ & 0.048 & $.841(.734-.964)$ & 0.03 \\
\hline Temperature $\left(60-70^{\circ} \mathrm{C}\right)^{*}$ & $1.39(.442-4.33)$ & 0.576 & & \\
\hline Temperature $\left(71-80^{\circ} \mathrm{C}\right)^{*}$ & $1.29(.292-5.66)$ & 0.74 & & \\
\hline Needle positions & $1.19(.944-1.49)$ & 0.143 & & \\
\hline Wall to wall & $.561(.299-1.05)$ & 0.072 & $.580(.247-1.36)$ & 0.211 \\
\hline Bone (humerus)** & $.983(.450-2.15)$ & 0.963 & & \\
\hline Bone (tibia) ${ }^{* *}$ & $.945(.336-2.66)$ & 0.915 & & \\
\hline Location $\mathrm{DM}^{* * *}$ & $.312(.105-.926)$ & 0.036 & $.328(.103-1.04)$ & 0.059 \\
\hline Location MET*** & $.615(.280-1.35)$ & 0.225 & & \\
\hline Location $\mathrm{ME}^{* * *}$ & $.827(.311-2.20)$ & 0.703 & & \\
\hline \multicolumn{5}{|l|}{$\mathrm{R} 1 / 2$ vs $\mathrm{R} 2$} \\
\hline Tumor volume ${ }^{A}$ & $1.03(.991-1.06)$ & 0.149 & & \\
\hline Age $^{Æ \notin}$ & $1.01(.973-1.04)$ & 0.771 & & \\
\hline Mean time per position ${ }^{Æ £ Æ}$ & $.866(.745-1.01)$ & 0.063 & $.735(.499-1.08)$ & 0.118 \\
\hline Temperature $\left(60-70^{\circ} \mathrm{C}\right)^{*}$ & $2.08(.320-13.5)$ & 0.443 & & \\
\hline Temperature $\left(71-80^{\circ} \mathrm{C}\right)^{*}$ & $7.57(1.27-45.1)$ & 0.026 & $4.98(.778-31.8)$ & 0.09 \\
\hline Needle positions & $1.20(.910-1.59)$ & 0.196 & & \\
\hline Wall to wall & $1.12(.489-2.58)$ & 0.782 & & \\
\hline Bone (humerus) ${ }^{* *}$ & $.844(.293-2.43)$ & 0.753 & & \\
\hline Bone (tibia) ${ }^{* *}$ & $1.01(.270-3.80)$ & 0.985 & & \\
\hline Location $\mathrm{DM}^{* * *}$ & $.378(.071-2.02)$ & 0.254 & & \\
\hline Location MET*** & $1.00(.345-2.90)$ & 1 & & \\
\hline Location $\mathrm{ME}^{* * *}$ & $2.16(.657-7.10)$ & 0.205 & & \\
\hline
\end{tabular}


$\mathrm{OR}=$ odds ratio, $\mathrm{CI}=$ confidence interval

*Temperature: compared to temperature 81-90C.

**Bone: compared to femur

***Location: all compared to diaphysis (DM = transition diaphysis/metaphysis, MET = metaphysis, ME = transition metaphysis/epiphysis)

$\varnothing$ Tumor volume: OR per $\mathrm{cm} 3$ in volume

$\varnothing \varnothing$ Age: OR per year in age

$\varnothing \varnothing \varnothing$ Mean time per position: OR per minute

\section{Complications}

In 189 procedures a total of 15 complications (7.9\%) occurred (table 3). The most frequent complication was a fracture (nine cases, $4.8 \%$ ), followed by AVN (four cases, $2.1 \%$ ). Seven out of nine fractures were found in the femur, the other two in the humerus. One case of thermal injury involved damage to the radial nerve, leading

Table 3: Complications. to loss of both sensory and motoric function. During four years of follow-up only partial motor function returned. The frequency distribution of the complications over the different bones is shown in table 5. Almost all fractures occurred in the femur and three out of four AVNs were in the humerus. Four out of nine fractures occurred on the transition diaphysis/metaphysis, three were in the diaphysis. All AVNs occurred in the proximal metaphysis/epiphysis.

\begin{tabular}{|c|c|}
\hline Complication & Frequency \\
\hline Fracture & 9 \\
\hline Avascular necrosis & 4 \\
\hline Thermal injury & 2 \\
\hline Total & $15(7.9 \%)$ \\
\hline
\end{tabular}

Table 4: Effect of peri-procedural parameters on complication risk (general and fracture).

\begin{tabular}{|c|c|c|c|c|c|}
\hline Complication yes/no & Univariate OR (95\% CI) & P-value & Fracture & Univariate OR $(95 \% \mathrm{CI})$ & P-value \\
\hline Tumor volume & $1.01(.956-1.06)$ & 0.823 & Tumor volume & $1.02(.961-1.08)$ & 0.543 \\
\hline Age & $1.04(.994-1.09)$ & 0.09 & Age & $1.06(.995-1.14)$ & 0.07 \\
\hline Mean time per position & $1.06(.902-1.25)$ & 0.475 & Mean time per position & $1.04(.848-1.29)$ & 0.686 \\
\hline $\begin{array}{c}\text { Temperature }(60- \\
\left.70^{\circ} \mathrm{C}\right)^{*}\end{array}$ & $.963(.178-5.21)$ & 0.965 & Temperature $\left(60-70^{\circ} \mathrm{C}\right)^{*}$ & $2.04(.315-13.2)$ & 0.455 \\
\hline $\begin{array}{l}\text { Temperature (71- } \\
\left.80^{\circ} \mathrm{C}\right)^{*}\end{array}$ & $2.17(.371-12.7)$ & 0.391 & Temperature $\left(71-80^{\circ} \mathrm{C}\right)^{*}$ & $2.04(.190-21.8)$ & 0.556 \\
\hline Needle positions & $.875(.565-1.35)$ & 0.549 & Needle positions & $1.08(.668-1.75)$ & 0.75 \\
\hline Wall to wall & $.489(.169-1.41)$ & 0.186 & Wall to wall & $.730(.189-2.82)$ & 0.648 \\
\hline Bone (humerus) ${ }^{* *}$ & $1.96(.616-6.24)$ & 0.254 & Bone (humerus)** & $.818(.166-4.02)$ & 0.392 \\
\hline Bone (tibia)** & $.741(.089-6.20)$ & 0.782 & Bone (tibia)** & & 0.998 \\
\hline Location $\mathrm{DM}^{* * *}$ & $1.67(.408-6.80)$ & 0.476 & Location $\mathrm{DM}^{* * *}$ & $1.76(.365-8.52)$ & 0.481 \\
\hline Location MET*** & $.342(.073-1.61)$ & 0.174 & Location MET ${ }^{* * *}$ & $.308(.015-1.51)$ & 0.108 \\
\hline Location ME*** & $.667(.114-3.91)$ & 0.653 & Location ME*** & $.440(.043-4.46)$ & 0.488 \\
\hline
\end{tabular}

Table 5: Distribution of complications over the different bones.

\begin{tabular}{|c|c|c|c|c|c|c|}
\hline Bone & Femur & Humerus & Tibia & Acetabulum & Fibula & Total \\
\hline Complication & $9(7.0 \%)$ & $5(12.8 \%)$ & $1(5.3 \%)$ & $0(0 \%)$ & $0(0 \%)$ & $15(7.9 \%)$ \\
\hline Fracture & 8 & 1 & 0 & 0 & 0 & 9 \\
\hline Avascular necrosis & 1 & 3 & 0 & 0 & 0 & 0 \\
\hline Nerve injury & 0 & 1 & 0 & 0 & 1 & 1 \\
\hline Thermal injury & 0 & 0 & 1 & $1(100 \%)$ & $1(100 \%)$ & $174(92.1 \%)$ \\
\hline No complication & $120(93.0 \%)$ & $34(87.2 \%)$ & $18(94.7 \%)$ & 1 & 1 \\
\hline Total & 129 & 39 & 19 & & 189 \\
\hline
\end{tabular}




\section{Discussion}

The current study represents a large series of 189 RFA procedures for ACT, of which 163 were carried out minimally invasive. No other studies on minimal invasive treatment of ACTs/ chondrosarcoma grade 1 have been published other than the smaller series of our group by Dierselhuis et al. [11, 23].

\section{Treatment result}

With regard to effective ablation our aim was to achieve ablation with at least $2 \mathrm{~mm}$ margin around the tumor. Therefore the success rate of treatment could be calculated as $\mathrm{R} 0 /(\mathrm{R} 0+\mathrm{R} 1+$ R2), which was $66.7 \%(124 / 186)$ in this study. This result is lower than results for surgical treatment by curettage or wide resection (90 to 95\%) [3-5]. Nevertheless, a margin <2mm may be sufficient as well, since the tumor still appears completely ablated. However, a small margin might result in more local recurrences. Therefore, a separate R1 group was created. When defining success to be a complete ablation, the success rate could be calculated as (R0 + R1) / R2 $=157 / 186=84.4 \%$, which is close to that of curettage of ACT. For the CT-guided percutaneous procedures the success rate would be $136 / 161=84.5 \%$. To determine if R1 is a good result on the long term, extensive follow-up period is required. In our series, none of the R1 cases showed local residual disease activity on MRI during a minimum follow-up period of two years.

RFA result was dependent on tumor volume. A larger volume leads to a significantly higher risk of R1 or R2 ablation ( $p=.033$ ). For every $\mathrm{cm} 3$ increase in volume risk of $\mathrm{R} 1 / 2$ ablation increases by $4.4 \%$ (OR $=1.044$ ). Therefore, risk of an $\mathrm{R} 1 / 2$ ablation is double for tumors over $16 \mathrm{~cm} 3$ and threefold for tumors over $25 \mathrm{~cm} 3$. However larger tumor volume does not significantly increase risk of an incomplete ablation (R2) compared to a complete ablation (R0/1) ( $p=.149)$. Therefore, larger tumors are also eligible for RFA.

However, given these findings more caution is advised in deciding between minimal invasive- and open treatment for larger tumors over $20 \mathrm{~cm} 3$. Switching to open treatment however, leads to a higher risk of complications, especially fractures (4-11\% risk of a fracture in curettage vs $10.5 \%$ in (wide) resection vs $4.8 \%$ in minimally invasive RFA) [5, 25].

Our results show that ablations at lower temperature result in more incomplete ablations ( $\mathrm{p}=.026$ for $71-80^{\circ} \mathrm{C}$ vs $81-90^{\circ} \mathrm{C}$ ). Ablations with $81-90^{\circ} \mathrm{C}$ result in $75 \%$ of cases in R0. Since all ablations were carried out with temperature over $60^{\circ} \mathrm{C}$, this finding is contrary to the perception of instantaneous protein coagulation to occur with temperatures over $60^{\circ} \mathrm{C}$ as presented in figure 1 . However, temperature measurement is done at the tip of the probe. The ablation zone is larger than only the electrical zone as it is formed by electrical conduction around the active zone of the needle tip and the subsequent heat distribution with a certain gradient within the surrounding tissue. With this distribution temperature decreases at longer distance from the needle tip. Relatively low ablation temperatures result in smaller ablation zones and more chance of incomplete ablation. Since higher temperatures do not significantly increase the risk of complications $(p=.965$ for temperature $>80^{\circ} \mathrm{C}$ compared to $60-70^{\circ} \mathrm{C}, \mathrm{p}=.391$ for temperature $>80^{\circ} \mathrm{C}$ compared to $71-80^{\circ} \mathrm{C}$ ), safety is not compromised in high temperature ablations $\left(81-90^{\circ} \mathrm{C}\right)$. A point of consideration is that for R0/1 vs R2, result is significantly different between $71-80^{\circ} \mathrm{C}$ and $81-90^{\circ} \mathrm{C}$, but not between $60-70^{\circ} \mathrm{C}$ and $81-90^{\circ} \mathrm{C}(\mathrm{p}=.443) . \mathrm{A}$ possible explanation is the fact that there were relatively a lot of $\mathrm{R} 1$ ablations in the $60-70^{\circ} \mathrm{C}$ groups $(21.1 \%)$. The fact that only for R0/1 vs R2 a significant effect was found is due to the relatively high amount of R1 ablations in the $81-90^{\circ} \mathrm{C}$ group (19.6\%). Another point of consideration is that temperature was only recorded in the patient files in 88 procedures $(=46.6 \%)$. With more data differences might become more evident.

Shorter time per position leads to more R1/2 ablations (OR $=.894, \mathrm{p}=.048$ ), so longer ablation per position results in more R0. This could be explained by the fact that temperature slowly distributes through the bone during the ablation. Immediately after finishing the ablation, tissue temperature starts to cool again. The amount of needle positions does not affect the ablation result ( $\mathrm{p}=$ .143 for $\mathrm{R} 0$ vs $\mathrm{R} 1 / 2, \mathrm{p}=.196$ for $\mathrm{R} 0 / 1$ vs R2) and the complication risk is not dependent of increased time per position ( $p=.475)$. Therefore, in the perspective of safe and effective ablation, it is recommendable to perform ablations with longer time per position instead of a large number of positions for large tumors. Experiments are designed to confirm this hypothesis.

Ablations of ACTs with location on the transition from diaphysis to metaphysis result in R0 significantly more often compared to other locations. In $81.2 \%$ of cases R0 was reached, compared to $57.5 \%$ in diaphysis, $68.8 \%$ in metaphysis and $62.1 \%$ on the transition between metaphysis and epiphysis. There was no difference in tumor volume, amount of needle positions, ablation time per position or temperature between the different locations.

\section{Complications}

Temperature $\left(\mathrm{p}=.965\right.$ for temperature $>80^{\circ} \mathrm{C}$ compared to 60 $70^{\circ} \mathrm{C}, \mathrm{p}=.391$ for temperature $>80^{\circ} \mathrm{C}$ compared to $71-80^{\circ} \mathrm{C}$ ), amount of needle positions ( $\mathrm{p}=.549)$ and tumor volume $(\mathrm{p}=.823)$ have no significant effect on complication occurrence. Therefore, our data do not indicate the complications were caused by overaggressive treatment.

None of the peri-procedural variables affected the risk of a fracture. The average age of the patients with a fracture was 60.8 years, compared to 53.0 years for patients without a fracture. However, this difference was not significant $(p=.070)$ and is most likely due to the increasing incidence of fractures with age in the population in general [24]. A possible solution could be to plan a DEXA-scan before RFA-treatment in patients over 60 years old. 
The amount of complications after RFA of ACT (7.9\%) was similar to curettage surgery (5-11\%) and low compared to wide resection $(31.6 \%)[5,25]$. To further reduce the risk of complications our recommendation is to evaluate proximity to structures particularly prone to heat damage (e.g. nerves, cartilage, epiphyseal plate) carefully before the procedure. If the tumor is not close to such a structure it may be safe to use more aggressive ablation (longer time and higher temperature). Furthermore, since a fracture $(4.8 \%$ of cases) was the most frequent complication it could be an option to introduce an immobilization period after treatment, especially in femur, giving the bone better opportunity to recover.

\section{Points of consideration}

A possible weakness of the current study is the fact that the parameter ablation time is hard to describe. Dependent on the shape and volume of the tumor, ablation is done using single- or multiple positions. In the current analysis ablation time is described as the time per position. Since positions are normally close to each other, an area is already (partially) preheated when ablation on the next position starts. Furthermore, the peri-procedural parameters evaluated in this study only account for a small portion of variance in treatment result $(\mathrm{R} 2=.153$ for $\mathrm{R} 0$ vs $\mathrm{R} 1 / 2$ and $\mathrm{R} 2=.171$ for $\mathrm{R} 0 / 1$ vs R2). In future evaluations more variables should be included to form a stronger model. Also, longer follow-up is necessary to be able to evaluate long-term effect of RFA treatment. A final point for consideration is the unpredictability of treatment result (i.e. the fact we encountered $17.7 \% \mathrm{R} 1$ ablations). The aim is to be able to use this technique more accurately in the future as a result of increased experience and research, hereby guarantying complete ablation with the desired safety margin. To further expand the value of RFA for ACTs and to improve treatment result it would be interesting to use real-time feedback on halo size during the procedure. Option for this is MRI thermometry and dual energy CT [26-28]. However, so far these methods come with limitations like motion artefacts and unpredictability and need to be examined in further detail.

\section{Conclusion}

RFA provides promising results for the treatment of ACT with complete ablation (R0, R1) in $84.4 \%$ of procedures. Complication rate $(7.9 \%)$ is comparable with open surgery. This is similar to results and complication rates as described in literature on surgical treatment [3-5]. There is less damage to surrounding tissue, costs are lower and it is more patient friendly because of the minimal invasive character. More research is needed to determine the optimal procedure parameters for ablation duration, needle positions and temperature. However, these encouraging data support the potential of RFA to replace more invasive surgical approaches for ACT treatment.

\section{Contributors Statement}

\author{
Literature search: H Nijland
}

Study design: H Nijland, PC Jutte

Data collection: J Overbosch, JJW Ploegmakers, TC Kwee, PC Jutte

Data analysis/interpretation: H Nijland, TC Kwee, PC Jutte

Writing: H Nijland, J Overbosch, JJW Ploegmakers, TC Kwee, PC Jutte

\section{Disclosure statement}

The authors declare that they have no relevant or material financial interests that relate to the research described in this paper.

\section{References}

1. Primary bone cancer. [Internet]. US National cancer institute; 2019 Nov 20.

2. Van Praag V, Rueten-Budde AJ, Ho V, Dijkstra PDS, Fiocco M, et al. (2018) Incidence, outcomes and prognostic factors during 25 years of treatment of chondrosarcomas. Surg Oncol 27(3): 402-408.

3. Dierselhuis EF, Gerbers JG, Ploegmakers JJ, Stevens M, Suurmeijer AJ, et al. (2016) Local Treatment with Adjuvant Therapy for Central Atypical Cartilaginous Tumors in the Long Bones: Analysis of Outcome and Complications in One Hundred and Eight Patients with a Minimum Follow-up of Two Years. J Bone Joint Surg Am 98(4): 303-313.

4. Stomp W, Reijnierse M, Kloppenburg M, de Mutsert R, Bovée JV, et al. (2015) Prevalence of cartilaginous tumours as an incidental finding on MRI of the knee. NEO study group. Eur Radiol 25(12): 3480-34877.

5. Chen X, Yu LJ, Peng HM, Jiang C, Ye CH, et al. (2017) Is intralesional resection suitable for central grade

6. 1 chondrosarcoma: A systematic review and updated meta-analysis. Eur J Surg Oncol. 2017 43(9):1718-1726.

7. Campanacci DA, Scoccianti G, Franchi A, Roselli G, Beltrami G, et al. (2013) Surgical treatment of central grade 1 chondrosarcoma of the appendicular skeleton. J Orthop Traumatol 14(2): 101-107.

8. Dierselhuis EF, Goulding KA, Stevens M, Jutte PC (2019) Intralesional treatment versus wide resection for central low-grade chondrosarcoma of the long bones. Cochrane Database Syst Rev 3(3): CD010778.

9. Deckers C, Schreuder BH, Hannink G, de Rooy JW, van der Geest IC, et al. (2016) Radiologic follow-up of untreated enchondroma and atypical cartilaginous tumors in the long bones. J Surg Oncol114(8): 987-991.

10.Reeves RA, DeWolf MC, Shaughnessy PJ, Ames JB, Henderson ER, et al. (2017) Use ofminimally invasive spine surgical instruments for the treatment of bone tumors. Expert Rev Med Devices 14(11): 881-890.

11.Zou T, Li Q Zhou X, Yang Z, Wang G, et al. (2015) Remove orthopedic fracture implant with minimal invasive surgery is good for the patient's early rehabilitation. Int J Clin Exp Med 8(12): 22377-22381.

12. Dierselhuis EF, Overbosch J, Kwee TC, Suurmeijer AJH, Ploegmakers JJW, et al. (2019) Radiofrequency ablation in the treatment of atypical cartilaginous tumours in the long bones: lessons learned from our experience. Skeletal Radiol 48(6): 881-887.

13. Callstrom MR, Charboneau JW ( 2005) Percutaneous Ablation: Safe, Effective Treatment of Bone Tumors. Oncology (Williston Park). 2005 11(Suppl 4): 22-26. 
14. Rosenthal DI, Alexander A, Rosenberg AE, Springfield D (1992) Ablation of osteoid osteomas with a percutaneously placed electrode: a new procedure. Radiology 183(1): 29-33.

15. Nijland H, Gerbers JG, Bulstra SK, Overbosch J, Stevens M, et al. (2017) Evaluation of accuracy and precision of CT-guidance in Radiofrequency Ablation for osteoid osteoma in 86 patients. Plos One 12(4): e0169171.

16. Nakatsuka A, Yamakado K, Uraki J, Takaki H, Yamanaka T, et al. (2016) Safety and Clinical Outcomes of Percutaneous Radiofrequency Ablation for Intermediate and Large Bone Tumors Using a Multiple-Electrode Switching System: A Phase II Clinical Study. J Vasc Interv Radiol 27(3):388-394

17. Tanigawa N, Arai Y, Yamakado K, Aramaki T, Inaba Y, et al. (2018) Phase I/II Study of Radiofrequency Ablation for Painful Bone Metastases: Japan Interventional Radiology in Oncology Study Group 0208. Cardiovasc Intervent Radiol 41(7): 1043-1048.

18. Eriksson AR, Albrektsson T (1983) Temperature threshold levels for heat-induced bone tissue injury: A vital-microscopic study in the rabbit. J Prosthet Dent 50(1):101-107.

19. Eriksson A, Albrektsson T, Grane B, McQueen D (1982) Thermal injury to bone. A vital microscopic description of heat effects. Int J Oral Surg 11(2):115-121.

20. Feldman L, Fuchshuber P, Jones DB (2012) The SAGES Manual on the Fundamental Use of Surgical Energy (FUSE). Springer 15: pp. 266
21. Issa ZF, Miller JM, Zipes DP (1983)Ablation energy sources. Book: Advances in Radiation Biology

22. Soldatos T, McCarthy EF, Attar S, Carrino JA, Fayad LM, et al. (2011) Imaging features of chondrosarcoma. J Comput Assist Tomogr 35(4): 504-511.

23. Dierselhuis EF, van den Eerden PJ, Hoekstra HJ, Bulstra SK, Suurmeijer AJ, et al. (2014) Radiofrequency ablation in the treatment of cartilaginous lesions in the long bones: results of a pilot study. Bone Joint J 96-B(11): $1540-1545$.

24. Curtis EM, van der Velde R, Moon RJ, van den Bergh JP, Geusens P, et al. (2016) Epidemiology of Fractures in the United Kingdom 1988-2012: Variation with age, sex, geography, ethnicity and socioeconomic status. Bone 87: 19-26.

25. Gerbers JG, Dierselhuis EF, Stevens M, Ploegmakers JJW, Bulstra SK, et al. (2018) Computer-assisted surgery compared to fluoroscopy in curettage of atypical cartilaginous tumors / chondrosarcoma grade 1 in the long bones. PLoS One 13(5): e0197033.

26. Zhu M, Sun Z, Ng CK (2017) Image-guided thermal ablation with MRbased thermometry. Quant imaging med surg 7(3): 356-368.

27.Zhou Y (2017) Noninvasive Thermometry in High-intensity focused ultrasound ablation. Ultrasound Q 33(4): 253-260.

28. Paul J, Vogl TJ, Chacko A (2015) Dual energy computed tomography thermometry during hepatic microwave ablation in an ex-vivo porcine model. Phys Med 31(7):683-691.
(C) (1) This work is licensed under Creative

To Submit Your Article Click Here: Submit Article

DOI: $10.32474 /$ OAJOM.2020.03.000172

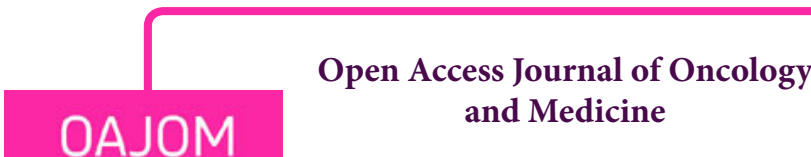

Assets of Publishing with us

- Global archiving of articles

- Immediate, unrestricted online access

- Rigorous Peer Review Process

- Authors Retain Copyrights

- Unique DOI for all articles 